\title{
Learning produced by escape and spontaneous alternation
}

\author{
WILLIAM A. HILLIX \\ San Diego State University, San Diego, California \\ and \\ M. RAY DENNY \\ Michigan State University, East Lansing, Michigan
}

\begin{abstract}
If rats in a T-maze made an arbitrarily designated correct response, that response was the terminal trial of the day. If, instead, they made the other incorrect response, they were shocked on the next trial whenever they failed to choose either arm of the maze within $3 \mathrm{sec}$. All rats quickly learned to choose one arm, but the incorrect arm was chosen as often as the correct. Thus the original hypothesis that escape from shock in conjunction with the tendency to alternate would mediate the learning of the correct response was not supported. However, the animals that learned the incorrect response had a much weaker tendency to alternate on shock trials than had the learners of the correct response. Fourteen of the 16 subjects fixated on the arm to which they went when first shocked, which seems consistent with elicitation theory.
\end{abstract}

Lett $(1973,1975,1979)$ has demonstrated what appears to be long-delay learning in the T-maze, and she has used this finding to argue against traditional theories of instrumental learning (e.g., Grice, 1948). The obvious way to account for Lett's results is to postulate that reinforcement can be effective after much longer delays than had heretofore been thought. However, Denny (1979) has suggested that the learning that was apparently dependent upon delayed reward might instead depend upon the joint effect of frustration and the tendency to alternate. Animals in the Lett procedure were fed in the stem, but only following a correct trial. However, an expectancy for food would be established that would occur following incorrect as well as correct responses. Thus, following an incorrect response, when the rat received another trial, no food would be present in the stem; and the rat, expecting food, would be frustrated. Frustration would elicit running (escape), and this running would probably take the animal to the correct side (the side opposite that of the previous incorrect trial) due to the strong alternation tendency in rats. According to Denny and Adelman (1955), the consistent elicitation of this escape response would produce the learning of this response.

Denny (1979) tried to test his hypothesis by feeding one group of rats outside the maze, in wastebaskets, and another under Lett's original conditions. The assumption was that animals fed in the wastebaskets would not be frustrated when failing to find food in the stem, and hence

The authors are indebted to Debbie Halstead for helping to collect the data. Requests for reprints should be addressed to William A. Hillix. Department of Psychology, San Diego State University, San Diego. CA 92115. would not learn. Unfortunately for the hypothesis, the animals did learn, albeit slowly. However, Denny observed that the animals fed in the wastebaskets seemed to be quite emotional or frustrated when they were not fed after being removed from their home cages and placed in the stem for the next trial. Handling, rather than the stem of the maze, had apparently become a cue to expect feeding. Senkowski and Denny (1977) have also shown that frustration is quite effective as a mediator of barpress learning. Thus the frustration-elicitation hypothesis as an account of long-delay learning remains tenable.

The experiment discussed in this paper is a direct test of the possibility that escape-avoidance behavior, plus alternation tendencies in the T-maze, is adequate to produce learning of a specific response. A mild shock replaces the presumed frustration. This experiment is a direct test because it does not rely on the rat's expectancy for food to produce escape tendencies. Coover, Sutton, Welle, and Hart (1978) have cited evidence that glucocorticoid responses to unexpected delays of reinforcement (frustration) are similar to those of shock, indicating that shock and frustration are similar in ways other than their elicitation of escape behaviors. This helps to justify the substitution of shock for frustration in the present investigation.

\section{METHOD}

\section{Subjects}

Subjects were 8 naive male Holtzman rats about 180 days old at the beginning of the study, and 8 female rats. Six of the females were Sprague-Dawley rats about 190 days old, 4 of which had previously served in an observation-learning experiment. The other 2 females were naive Holtzman rats just over 150 days old. Three other animals were disqualified because of procedual errors, and one "runt" was disqualified for failure to respond. 


\section{Apparatus}

The apparatus was modeled closely after the T-maze used by Lett (1975). It was an enclosed $T$ with a gray stem $15.75 \mathrm{~cm}$ high, $9.8 \mathrm{~cm}$ wide, and $58.3 \mathrm{~cm}$ long. A white goalbox was in the left arm and a black goalbox in the right. The white goalbox was $62 \mathrm{~cm}$ long, and the black one $44.5 \mathrm{~cm}$ long. Hardware cloth was used to cover the top of the maze, which was constructed of wood. The entire maze was painted gray, but black or white cardboard inserts were placed in the goalboxes. Opaque goalbox and stem doors were hand operated. On the floor of the stem a copper strip the length of the stem was nailed on each side, with a gap of about $.3 \mathrm{~cm}$ down the center. Shocks could be administered through these copper strips via a C. J. Applegate Co. electric stimulator, Model 100 . To prevent the rats from contacting only one of the strips, and thereby avoiding the shock, the two interior sides of the stem had $.65 \mathrm{~cm}$ unpainted plywood strips nailed to them.

\section{Procedure}

All animals were gentled by handling at least daily for 1-2 weeks. Animals lived in individual cages with ad lib food and water. After gentling, the animals were placed in the maze, one at a time, and allowed to explore for 5-10 min each. The following day, animals were given three preference trials. They were placed in the stem with the stem door closed. After about $5 \mathrm{sec}$, the stem door was opened and the animal was allowed to choose an arm. Three preference trials were given on the same day, with at least $10 \mathrm{~min}$ between trials. After determining whether each animal preferred white or black, half the animals were randomly assigned to learn to go to the preferred arm, and the other half to learn to go to the nonpreferred arm.

The day after preferences were determined, animals began the learning portion of the experiment. On each day each animal was given repeated trials, with a minimum of 2 min between trials, until a correct response was made. A correct response terminated a day's trials. Thus a given animal could have from one trial per day (if the first response was correct, and thus receive no shocks that day) to a large number of trials per day.

On a given trial, an animal was placed in the stem with the choicepoint door closed. After $5 \mathrm{sec}$, this door was opened. Subjects received shocks in the stem only on the trial after an incorrect response. If the response on the previous trial was incorrect, an animal had $3 \mathrm{sec}$ after the choice-point door opened to make an avoidance response; if it did not respond in time, it received repeated mild shocks at intervals of $3 \mathrm{sec}$. Each momentary shock was $.24 \mathrm{~mA}$ for the males and $.22 \mathrm{~mA}$ for the females. If an animal did not respond within $3 \mathrm{~min}$, the trial was counted

Table 1

Individual Data

\begin{tabular}{cccc}
\hline Subjects & $\begin{array}{c}\text { Trials to } \\
\text { Criterion }\end{array}$ & $\begin{array}{c}\text { Total Number } \\
\text { Shock Trials }\end{array}$ & $\begin{array}{c}\text { Number of } \\
\text { Failures to Alternate } \\
\text { on Shock Trials }\end{array}$ \\
\hline & \multicolumn{3}{c}{ Males } \\
1 & 10 & 7 & 6 \\
2 & 14 & 4 & 4 \\
3 & 11 & 6 & 5 \\
4 & 25 & 10 & 6 \\
5 & 10 & 7 & 7 \\
6 & 16 & 3 & 3 \\
7 & $20^{*}$ & 2 & 0 \\
8 & $11^{*}$ & 3 & 0 \\
& & Females & \\
1 & $17^{*}$ & 4 & $2 \dagger$ \\
2 & $15^{*}$ & 2 & 2 \\
3 & 26 & 5 & 0 \\
4 & $37^{*}$ & 2 & 6 \\
5 & 10 & 6 & 0 \\
6 & $20^{*}$ & 2 & $3 \dagger$ \\
7 & $14^{*}$ & 4 & 0 \\
8 & $18^{*}$ & 5 &
\end{tabular}

*Learned designated, or correct, response. †Alternated on second shock trial rather than first. as an error and the animal removed from the apparatus. Animals were removed from the goalbox about $10 \mathrm{sec}$ after they entered it. They were considered to have entered when the entire animal, exclusive of the tail, was within the goalbox.

Training was terminated when animals had gone to one arm in 8 out of 10 trials, whether or not that arm was the one determined as "correct" by the experimenters. Animals who reached "criterion" by going most often to the wrong arm did so by continuing to make responses on a single day, while animals who reached criterion by making the correct response necessarily did so over a series of at least 8 days. There is no indication that even an indefinite number of trials would have persuaded animals that had chosen either the correct or the incorrect response to switch arms. Three of the first set of animals run were given 20 or more additional postcriterial trials, and none of them switched for more than a trial or two.

The order in which animals were run was changed daily so that all permutations of orders were used within squads of four animals. For the sake of time economy, trials for two animals being run successively were interlaced, with one animal waiting in the home cage while the other ran. Food and water were removed from the home cages while the animals were being run, and were not replaced for at least $30 \mathrm{~min}$ after the last trial of the day.

\section{RESULTS AND DISCUSSION}

In Table 1 it can be seen that all subjects were shocked on at least two trials, and all subjects reached the criterion of learning in a relatively small number of trials (the numbers in Table 1 include criterial trials). An equal number of rats learned the designated, or "correct," response as the other, or "incorrect," response. Therefore, the notion that escape from shock in conjunction with the alternation tendency would produce learning of the correct response was not supported.

With two exceptions (Females 1 and 8 ), the response made on the first shock trial was the response fixated by the animal. The two exceptions alternated on the immediately following trial, on which they were also shocked. Animals that learned the "correct" response were about five times more likely to alternate when shocked than animals that learned the incorrect response (see Tables 1 and 2). Thus it appears that alternation, in conjunction with escape from shock, can mediate the learning of a particular response, but it will mediate such learning only if the alternation tendency is sufficiently strong. Four of the 8 animals that fixated on the incorrect response never alternated on a shock trial. Perhaps shock reduces the tendency to alternate when compared with a situation in which the rat is fed and frustrated. Animals in a feeding situation are probably "in the mood" (Staddon \& Simmelhag, 1971) to alternate.

In fact, the learners of the correct response (the shock alternaters) learned their response in half the number of shock trials as the learners of the incorrect response, even though they took slightly, but not significantly, more trials to reach criterion than the incorrect learners (see Table 2). This finding means that, since shock was avoided more frequently by correct than by incorrect learners, the responding of the alternaters was generally faster than for the nonalternaters. Perhaps this is evidence of a summation effect (i.e., elicitation of the response by both an alternation bias and shock). 
Table 2

Statistical Analysis: "Correct" Learners versus "Incorrect" Learners

\begin{tabular}{lcccc}
\hline Means & $\begin{array}{c}\text { Correct } \\
\text { Learners }\end{array}$ & $\begin{array}{c}\text { Incorrect } \\
\text { Learners }\end{array}$ & $F$ & $p$ \\
\hline $\begin{array}{l}\text { Number Shocks } \\
\text { Received }\end{array}$ & $3.00(1.2)$ & $6.00(2.1)$ & 12.0 & .004 \\
$\begin{array}{l}\text { Number Trials } \\
\text { to Criterion }\end{array}$ & $19.00(7.9)$ & $15.25(6.7)$ & 1.05 & NS \\
$\begin{array}{l}\text { Proportion of } \\
\begin{array}{l}\text { Alternations on } \\
\text { Shock Trials }\end{array}\end{array}$ & $.80(.28)$ & $.163(.23)$ & 25.3 & .0001 \\
\hline
\end{tabular}

Note-Standard deviations are in parentheses; $d f=1,14$.

The results are clearly reminiscent of the early work on fixation and regression in the rat, in which the animals were typically shocked in the stem of the T-maze just preceding the choice-point and thereafter maintained whatever response they made on the shock trial (Everall, 1935; Hamilton \& Krechevsky, 1933; O'Kelly, 1940; Sanders, 1937). Studies involving frustration rather than shock (Epstein, 1985; Maier, Glaser, \& Klee, 1940) seem to have found comparable fixation or regression effects.

In short, the results of the present study indicate the feasibility of a rat's learning to go one way in a two-choice situation after escaping a few mild shocks by going mostly, if not exclusively, in one direction, and regardless of whether the rat is removed from the experimental situation for the day once that response has been made. By extension, learning through frustation-instigation should be entertained as a reasonable possibility whenever the conditions permit it (Senkowski \& Denny, 1977). In particular the results are interpreted as being consistent with the tenets of elicitation theory (Denny, 1971; Denny \& Adelman, 1955). What gets elicited initially, gets learned, whether it involves alternation responses or not.

\section{REFERENCES}

Coover, G. D., Sutton, B. R., Welle, S. L., \& Hart, R. P. (1978). Corticosterone responses, hurdle-jump acquisition, and the effects of dexamethasone using classical conditioning of fear. Hormones \& $\mathrm{Be}$ havior, 11, 279-294.

DENNY, M. R. (1971). A theory of experimental extinction and its relation to a general theory. In H. Kendler \& J. Spence (Eds.), Essays in neobehaviorism: A memorial volume to Kenneth $W$. Spence. New York: Appleton-Century-Crofts.

Denny, M. R. (1979). Long delay learning in a T-maze. Academic Psychology Bulletin, 1, 135-142.

Denny, M. R., \& Adelman, H. S. (1955). Elicitation theory: I. An analysis of two typical learning situations. Psychological Review, 51 , 87-93.

EPSTEIN, R. (1985). Extinction-induced resurgence: Preliminary investigations and possible applications. The Psychological Record, 35, 143-153.

Everall, E. E. (1935). Perseveration in the rat. Journal of Comparative Psychology, 19, 343-369.

GricE, G. R. (1948). The relation of secondary reinforcement to delayed reward in visual discrimination learning. Journal of Experimental Psychology, 38, 1-16.

Hamilton, J. A., \& Krechevsky, I. (1933). Studies in the effect of shock upon behavior plasticity in the rat. Journal of Comparative Psychology, 16, 237-253.

LETT, B. T. (1973). Delayed reward learning: Disproof of the traditional theory. Learning \& Motivation, 4, 237-246.

LETT, B. T. (1975). Long delay learning in the T-maze. Learning \& Motivation, 6, 80-90.

LETT, B. T . (1979). Long-delay learning: Implications for learning and memory theory. In N. S. Sutherland (Ed.), Tutorial essay in psychology: A guide to recent advances (Vol. 2). New York: Halstead Press.

Maier, N. R. F., Glaser, N. W., \& Klee, J. B. (1940). Studies of abnormal behavior in the rat: III. The development of behavior fixations through frustration. Journal of Experimental Psychology, 26, 521-546.

O'KeLLY, L. I. (1940). An experimental study of regression: II. Some motivational determinants of regression and perseveration. Journal of Comparative Psychology, 30, 55-95.

SANDERS, M. J. (1937). An experimental demonstration of regression in the rat. Journal of Experimental Psychology, 21, 493-510.

SENKowsKI, P., \& DENNY, M. R. (1977). Frustration-mediated learning of a barpress response. Animal Learning \& Behavior, 5, 373-376.

Staddon, F. E. R., \& Simmelhag, V. L. (1971). The "superstition", experiment: A reexamination of its implications for the principles of adaptive behavior. Psychological Review, 78, 3-43.

(Manuscript received for publication June 21, 1985.) 